\title{
Vulvar carcinoma: dilemma, debates, and decisions
}

This article was published in the following Dove Press journal:

Cancer Management and Research

\section{Swarupa Mitra' \\ Manoj Kumar Sharma' \\ Inderjeet Kaur' \\ Ruparna Khurana' \\ Kanika Batra Modi² \\ Raman Narang' \\ Avik Mandal' \\ Soumya Dutta'}

'Department of Radiation Oncology, Rajiv Gandhi Cancer Institute and Research Center, New Delhi, India, ${ }^{2}$ Department of Genitourinary Surgical Oncology, Rajiv Gandhi Cancer Institute and Research Center, New Delhi, India
Correspondence: Swarupa Mitra Department of Radiation Oncology, Genitourinary services, Rajiv Gandhi Cancer Institute and Research Center Sector-5, Rohini, New Delhi I 10085 , India

Tel +9l 97 I704 I602

Email swarupamitra@gmail.com

\begin{abstract}
Vulvar carcinoma is a rare and aggressive gynecological malignancy. It affects elderly females, with the mean age at diagnosis being 55-60 years. Regional metastasis to inguinal lymph nodes is common. There is a high incidence of pelvic node involvement, especially in those with pathologically positive inguinal nodes. Surgery appears to be the only curative treatment option in the early stages of the disease. But in most patients, surgery is associated with considerable morbidities and psychosexual issues. Hence, in the quest for a less morbid form of treatment, multimodality approaches with various combinations of surgery, chemotherapy, and radiation therapy have been suggested for advanced vulvar cancers. Due to the low incidence of the disease, the level of evidence for the success of these treatment modalities is poor. In countries like India, a heterogeneous incidence of vulvar carcinoma exists across the country, with patients presenting at advanced stages when the option of surgery is often supplemented or replaced by chemotherapy and radiotherapy. In this review, we attempt to study the available published literature and trials and discuss the treatment options in various stages of vulvar carcinoma.
\end{abstract}

Keywords: vulva, vulvectomy, radiotherapy, WLE, chemoradiation, review, management

\section{Introduction}

Worldwide, vulvar carcinoma is rare, constituting approximately $4 \%$ of all gynecological malignancies. However, the rates for new cases of vulvar cancer have been increasing by about $0.6 \%$ every year over the past 10 years. Death rates too have been rising, at the average rate of $1.2 \%$ each year between 2005 and $2014 .{ }^{1}$ About $43 \%$ of vulvar carcinomas are due to human papilloma virus (HPV). ${ }^{2} \mathrm{HPV} 16$ and 33 are the predominant subtypes, accounting for $55.5 \%$ of all HPV-related vulvar cancers. More than $60 \%$ of all vulvar cancers occur in the more developed nations. Squamous cell carcinoma constitutes $70 \%$ of vulvar carcinomas. There are 2 distinct histological patterns of vulvar carcinomas, with 2 different risk factor profiles. 1) The basaloid/warty lesions are more common in young women, being commonly associated with HPV DNA (75\%-100\%). This subtype simulates the risk factor profile of cervical cancer. 2) The keratinizing vulvar carcinomas represent the majority of the vulvar lesions ( $>60 \%)$. They occur more often in older women and are rarely associated with $\mathrm{HPV}^{3}$ The other different less common histologies are melanoma, basal cell, Bartholin gland adenocarcinoma, sarcoma, and Paget's disease. The risk of developing vulvar carcinoma is related to different behavioral, reproductive, hormonal, and genetic aspects. Factors that increase the risk include other genital cancers, chronic inflammatory diseases of the vulva, smoking, history of genital warts, and vulvar 
intraepithelial neoplasia. Paget's disease of the vulva is a rare disease, with incidence reports varying between $<1 \%$ and $2 \%$ of vulvar malignancies. ${ }^{4}$ It is most common in postmenopausal Caucasian women. The underlying cause is not very well understood. In $\sim 25 \%$ of women, Paget's disease of the vulva is invasive and the prognosis in such cases is worse than in non-invasive cases. Unfortunately, recurrence rates are very high (33\%), even in cases with clear margins, and still higher in cases with close or positive surgical margins, regardless of invasion. Traditionally, surgical excision with or without inguinofemoral lymph node dissection, has remained as the treatment of choice. Radiotherapy has been used as a primary treatment option for patients who were not eligible for surgery or who refused surgery and also a treatment option for patients with recurrence after surgery. Recent studies, however, show that imiquimod cream may be an effective and safe alternative. ${ }^{5}$

Cancer registry in India, as in 2015, showed a heterogeneous incidence of vulvar carcinoma across the country. During the year 2003-2007, the crude rate per 100,000 women per year in Delhi was found to be 0.3 , while it was 0.4 in Bangalore, 0.5 in Mizoram and 0.2 using. ${ }^{6}$ A pooled incidence in different cities showed a rise in incidence between the age groups of 50 and 70 years. While both cervical and vulvar cancers are caused by HPV, research is required to understand why the former is more common than the latter.

Due to the rarity of the cancer and lack of randomized trials, management of this aggressive disease is shrouded with dilemmas and controversies. Although surgery has remained the cornerstone in the management of vulvar carcinoma, especially in the early stages, the morbidities associated cannot be overlooked. This has led to changing paradigms in the surgical management from the mutilating radical en bloc procedures to triple incision techniques to the present radical local excisions, mainly to maintain the sexual identity and satisfactory body image of the affected patient, and to decrease the surgery-associated morbidity.

In countries like India, where patients present at an advanced stage, the option of surgery is often replaced by chemotherapy and radiotherapy. In a recent study from India, 51.2\% patients presented in stage III-IV when surgery was not a treatment option. ${ }^{7}$ Hence, this review article is being presented as an Indian perspective and it is our endeavor to bring out the dilemmas regarding the modes of management of vulvar carcinoma, with emphasis on the newer conservative forms of treatments.

\section{Prognostic factors}

The management of vulvar carcinoma is largely guided by the stage and the prognostic factors. While the most important prognostic factor is the presence and the number of inguinal node metastases, other factors include extra nodal tumor extension, tumor diameter, depth of invasion, tumor thickness, and lymphovascular space invasion. The margin status, tumor grade, and age of the patient ${ }^{8-10}$ are also of considerable significance in predicting the prognosis. The treatments offered in vulvar carcinoma also differ accordingly.

The age of the patient merits particular emphasis, since according to the recent literature, between 1973 and 2000, the incidence of vulvar cancer has been found to be increasing $(20 \%)$ in younger women. ${ }^{11}$ This change in pattern of incidence may be attributed partly to an increasing number of HPV infections in younger and sexually active women. Hence, less morbid and less radical surgeries are being considered for these young patients. Complete inguinofemoral node dissection leads to high rates of lymphedema $(30 \%-70 \%)$ and wound dehiscence $(20 \%-40 \%){ }^{12,13}$

\section{Staging systems}

Vulvar cancer has been classified using the TNM classification ${ }^{14}$ and the International Federation of Gynecology and Obstetrics (FIGO $)^{15}$ staging systems by taking into account the size of the tumor $(\mathrm{T})$, spread to lymph nodes $(\mathrm{N})$, and spread to distant sites (M). The depth of invasion is generally defined from the epithelial-stromal junction of the most superficial adjacent dermal papilla to the deepest point of invasion of the tumor. ${ }^{16}$ The disease spreads initially to the inguinal and femoral nodes, which are considered as regional sites. The involvement of pelvic lymph nodes is considered as distant metastasis. As a part of the revision in the FIGO staging system, it has been recommended that not only the number of nodes with metastasis but also the size of metastasis and presence or absence of extranodal spread should be specified by the pathologist. The depth of invasion is defined as the measurement of the tumor from the epithelial-stromal junction of the adjacent most superficial dermal papilla to the deepest point of invasion.

\section{Comparison of the staging systems}

The FIGO staging system was last reviewed in 2009 by the FIGO Committee on Gynecologic Oncology in close collaboration with the American Joint Commission on Cancer and the Union of International Cancer Control. ${ }^{17}$ This resulted in an amalgamation of clinical, surgical, and pathological staging systems, and a new FIGO classification was proposed with the following 4 major changes:

1. Vulvar carcinoma stages II $(>2 \mathrm{~cm})$ and IB $(\leq 2 \mathrm{~cm})$ were integrated because these 2 categories of patients did not show any differences in survival. ${ }^{18}$ Regardless of 
the diameter of the primary tumor, negative lymph node status was considered as low-risk criterion. ${ }^{19}$

2. Stage III vulvar carcinoma represented a heterogeneous group of patients with both negative and positive lymph nodes. The former stage III patients with tumors involving the lower vagina and/or urethra with negative nodes are now classified as stage II, ${ }^{20}$ as they have a better prognosis.

3. Patients with positive nodes are still classified as stage III. The number of the involved nodes along with the size of the metastasis and the presence or absence of extranodal growth has been taken into account in the new staging system. An increasing number of positive lymph nodes and a larger diameter of nodal metastases led to a worse survival rate. Stage III now consists of nodal metastases with extranodal spread. This category has an even worse prognosis compared with patients with metastases confined to the lymph nodes. ${ }^{21}$

4. The laterality of positive nodes has been disregarded in the new FIGO staging because it is not an independent prognostic factor when a correction is made for a number of positive lymph nodes. ${ }^{22}$

\section{Management of vulvar carcinoma}

\section{Surgery}

The management of early-stage vulvar carcinoma is predominantly surgery. The extent of the surgery, lymph node dissection, and groin evaluation along with margins are important issues that need individualization in approach.

Until the 1990s, all patients with vulvar cancer underwent en bloc radical vulvectomy and bilateral inguinofemoral lymphadenectomy through a butterfly incision. The aim was to remove all possible tissues, including the skin bridge between vulva and groins. This procedure was associated with high rates of survival, but it was associated with significant morbidity, such as poor wound healing, lymphedema, and adverse effects on body image and sexual function. ${ }^{23,24}$
In 1962, Byron et al, ${ }^{25}$ for the first time, introduced surgery through 3 separate groin and vulval incisions in place of the butterfly incision. This was called as the triple incision technique and was less extensive than the older butterfly technique. Studies by Ansink and van der Velden and by Heaps et al confirmed that this surgical technique produced similar overall results with reduced morbidities and skin bridge recurrences. ${ }^{26,27,28}$ But inspite of the better surgical technique, there was a growing interest in less radical surgeries to avoid the morbidities and improve the quality of life. In 1994, Burke et al and Farias-Eisner et al established that wide local excision (WLE) in place of total vulvectomy in early-stage vulvar cancer produced equal results without compromising the oncological safety. ${ }^{29,30}$ There were 5 studies that compared radical or WLE to radical vulvectomy. None of these studies showed any difference in overall survival, disease free survival, or in local and distant recurrences (Table 1).

Lesions that are $<2 \mathrm{~cm}$ in diameter and confined to the vulva, with stromal invasion $\leq 1.0 \mathrm{~mm}$ (FIGO stage IA) and with no lymphatic space invasion, are managed by WLE only with a tumor-free margin all-around of at least $1 \mathrm{~cm}$. With close midline structures such as clitoris, urethra, or the anus, less wide margins may be considered.

The issue of margin status has also been a subject of controversies. While several studies ${ }^{31}$ had, in the past, demonstrated that a margin distance of $<8 \mathrm{~mm}$ may cause higher risk of recurrence, more recent studies by Woelber et al show minimum importance of the tumor-free margin. ${ }^{32,33}$

However, a consensus prevails regarding groin node dissection, which may be avoided in these early stages, because the risk of lymph node metastases is negligible in this group. ${ }^{34}$ Ipsilateral inguinofemoral dissection should be included if the depth of invasion turns out to be $>1 \mathrm{~mm}$ in the final pathology report.

When the depth of invasion is $>1 \mathrm{~mm}$ (FIGO stage IB or more) or the maximum diameter of the tumor is $>2 \mathrm{~cm}$,

Table I Retrospective studies comparing radical/WLE and radical vulvectomy

\begin{tabular}{|c|c|c|c|}
\hline Study & Stages & Number of patients & Results \\
\hline \multirow[t]{3}{*}{ Farias-Eisner ${ }^{68}$} & TI-2, N0-I & 74 & 5 -year OS - $97 \%$ vs $100 \%$ stage I \\
\hline & & & $95 \%$ vs $75 \%$ stage $2, P>0.05$ \\
\hline & & & Serious complications - $11 \%$ vs $25 \%$ \\
\hline \multirow[t]{2}{*}{ Balat et $\mathrm{al}^{38}$} & & 49 & 5 years OS $-75 \%$ vs $67 \%$ \\
\hline & & & LC $83 \%$ vs $80 \%$, complications less in WLE \\
\hline De Hullu et $\mathrm{al}^{69}$ & & 238 & LR $-1 \mathrm{I} .4 \%$ vs $7.5 \%, P=0.32$ \\
\hline Rutledge et $\mathrm{al}^{39}$ & TI-2, N0 & 179 & Equal survival \\
\hline De Simone et $\mathrm{al}^{40}$ & TI-2, No & 122 & $\begin{array}{l}\text { LR }-13 \% \text { vs } 85 P=0.33 \text {, lymphedema }-7.5 \% \text { vs } 26 \%, P=-0.007 \text {, wound } \\
\text { separation }-7.5 \% \text { vs } 23 \%\end{array}$ \\
\hline
\end{tabular}

Abbreviations: LC, local control; LR, likelihood ratio; OS, overall survival; WLE, wide local excision. 
dissection of the groin nodes should be mandatory. This is because the risk of lymph node metastasis rises beyond $1 \mathrm{~mm}$ invasion depth, $7 \%-8 \%$ for $1.1-3.0 \mathrm{~mm}$ invasion, and $26 \%-34 \%$ for $>3 \mathrm{~mm}$ invasion. ${ }^{35}$

In more advanced cases, local recurrence in the groin carries a very high mortality. Hence, appropriate groin management is of utmost importance. In case of enlarged groin nodes, either inguinofemoral lymphadenectomy followed by radiotherapy or groin node debulking followed by radiotherapy can be considered. Bilateral groin dissection is recommended for midline tumors and large lateral tumors, especially those involving the anterior labia minora. Bilateral groin dissection is also indicated if ipsilateral lymph nodes are positive. ${ }^{36}$

When imaging shows enlarged pelvic nodes, debulking of these nodes is recommended. For clinically positive lymph nodes, it has been suggested not to proceed with full lymphadenectomy, since the inguinal dissection with postoperative irradiation has the potential to cause severe lymphedema. In these cases, wherever possible, only the largest lymph nodes may be surgically removed before the patient is subjected to postoperative radiotherapy. ${ }^{37}$

\section{Role of sentinel lymph node (SLN) dissection}

Approximately $25 \%-30 \%$ of the patients with vulvar carcinoma present with lymph node metastases at diagnosis. ${ }^{41}$ Groin recurrence rate may be decreased to $<1 \%$ by complete groin dissection; although, this produces significant morbidities. ${ }^{42}$

The last statement also indicates that $\sim 80 \%-90 \%$ of patients with vulvar carcinoma having $<2 \mathrm{~mm}$ invasion may be spared the morbidities of groin dissection. The role of SLN dissection is probably important in this group of patients. There are some large prospective trials confirming the high sensitivity of SLN dissection compared with complete groin dissection. A meta-analysis showed an overall sensitivity of $92 \%$ for the identification of sentinel node metastases using complete inguinofemoral node dissection as the reference, ${ }^{43}$ resulting in a negative predictive value of $97 \%-98 \%$. Sensitivity was further enhanced with the use of both blue dye and Tc-99m, for tumor size $<4 \mathrm{~cm}$ and lesions located $>2$ $\mathrm{cm}$ from the midline. Sensitivity was less in patients with clinically palpable inguinal nodes. ${ }^{44}$ Another analysis summarizing published literature totalling 383 patients showed a false-negative rate of $2.4 \% .^{45}$

Available literature suggests that the groin recurrence rates for patients undergoing SLN dissection alone are comparable with groin recurrence rates for patients who have complete lymph node dissection. The GROningen International Study on SLNs in vulvar cancer (GROINSS-V) was the first ever large prospective multicentric study that studied 403 patients with vulvar tumor size of $<4 \mathrm{~cm}$, stromal invasion of $>1 \mathrm{~mm}$, and negative SLNs. The study compared patients who underwent SLN biopsy with those who underwent full superficial node dissection for detecting positive SLN. The study found a groin recurrence rate of $2.3 \%$ over a median follow-up period of 35 months and a very low rate of surgical complications in the SLN biopsy group. ${ }^{46}$

Imaging is recommended prior to SLN biopsy to rule out grossly affected lymph nodes. Any affected nodes have decreased uptake of radiotracer or dye and hence that may not be identified as sentinel (the statement needs clarification). No modality as of now has been proven to be the best to differentiate metastatic from normal lymph nodes.

Based on current data, women who had a negative SLN may be observed without any further evaluation. Caution, however, should be maintained when performing SLN dissections on tumors $>4 \mathrm{~cm}$ and located in the midline. Moreover, bilateral SLN dissection should be considered in lesions within $2 \mathrm{~cm}$ of the midline and in all lesions that cross the midline. If an SLN is not found, then a full groin node dissection is recommended ${ }^{47}$ and if the SLN is positive, then bilateral groin node dissection is recommended. Further information is needed regarding the appropriate treatment of positive SLNs and, in particular, on the management of micrometastases.

\section{Radiotherapy}

Due to the low incidence of this cancer, absence of randomized controlled trials, and low level of evidences, no standard indications and recommendations for the different adjuvant treatment modalities are available. With available data, patients with early-stage vulvar cancer, negative groin status, and favorable prognosis, usually do not require any adjuvant treatment.

But treatment of locally advanced vulvar cancer may require further treatment modalities such as radiotherapy and chemotherapy adjuvant to surgery, to improve local control rate and survival. ${ }^{48} \mathrm{LN}$ metastases, large primary tumors, deep invasion, lymphovascular invasion, and close surgical margins are associated with increased risk of recurrence. But the role of adjuvant radiotherapy in such patients is still unclear. In a study by Akila Viswanathan, a surgical margin $\leq 5 \mathrm{~mm}$ have been seen to have a very high local recurrence rate, and adjuvant radiation at a dose of $\geq 56 \mathrm{~Gy}$ 
may decrease vulvar recurrence rates. ${ }^{49}$ Radiotherapy alone or in combination with lymph node (LN) dissection is highly effective in preventing inguinal node recurrence in patients with squamous cell carcinoma of the vulva. ${ }^{50}$ Based on the study by Gynecologic Oncology Group (GOG), 37 adjuvant groin and pelvic radiotherapies are considered as the standard of care for node-positive vulvar squamous cell carcinoma for patients with 2 or more LNs involved, extracapsular extension, or inadequate $\mathrm{LN}$ dissection.

In several studies, substantial benefit has been achieved with the addition of postoperative radiotherapy in 2 or more cases with positive inguinal nodes. ${ }^{51}$

But the role of radiation in cases with single $\mathrm{LN}$ positive is unclear. Because of the limited number of patients with single LN involved, adequate power was not achieved to determine the benefit of radiotherapy. Fons et a ${ }^{52}$ could not demonstrate a significant benefit of adjuvant radiotherapy in patients with single LN metastasis in either disease-free or disease-specific survival. Recurrence rates were also found to be similar between the radiotherapy and the no-radiotherapy arms (39\% vs 32\%). A Surveillance Epidemiology and End Result program analysis ${ }^{53}$ demonstrated a favorable prognosis in patients with a single positive lymph node receiving radiotherapy. However, it should be noted that no information about the size and location of tumor is available in this study. Moreover, adjuvant radiation did not significantly help women who had more than $12 \mathrm{LNs}$ resected. In the recent and largest ever multicentric retrospective study by the AGO-CaRE- $1,{ }^{54}$ adjuvant radiotherapy was associated with an improvement in prognosis irrespective of the number of involved lymph nodes.

A randomized trial by Homesley et $\mathrm{a}^{55}$ compared radiotherapy with pelvic lymphadenectomy in 114 patients with inguinofemoral lymph node metastasis after radical vulvectomy and inguinofemoral lymphadenectomy. The dose of radiation was 45-50 Gy delivered bilaterally to the pelvic and inguinal nodes using anterior and posterior opposing fields. The difference in the groin recurrence rates was significant, favoring the adjuvant radiation therapy $(5.1 \%$ vs $23.6 \%$, $P=0.02$ ). Survival was also found to be better in patients who received postoperative radiotherapy (2-year survival $68 \%$ vs $54 \%, P=0.03)$. A large retrospective study from India revealed a significant survival for patients receiving postoperative radiotherapy (2-year survival $68 \%$ vs $54 \%, P=0.03$ ) and a lower rate of relapse ( $5 \%$ vs $24 \%, P=0.02) .{ }^{56}$

According to present evidences, adjuvant radiotherapy to the groins and pelvis must be recommended after radical groin dissection when there are 2 or more affected lymph nodes or in the case of 1 lymph node metastasis with extracapsular spread or large size. This could be explained by the way of the fact that in $20 \%-30 \%$ of the patients with inguinofemoral lymph node metastases, pelvic lymph nodes are also affected.$^{57}$ In such patients, irradiation of the vulva may also be considered, though evidences regarding this are low. In the case of only 1 intracapsular metastasis, the role of radiotherapy is currently unclear and needs further investigation.

The role of adjuvant chemoradiation is not as well defined in vulvar carcinomas with lymph node metatstasis, as in other squamous cell carcinomas, such as carcinoma of the cervix and anal canal. This is probably due to low incidence of this disease. Han et al compared the survival rates in a group of 54 patients who received chemoradiation or radiation alone as primary treatment or as an adjuvant. Survival was found to be better in patients receiving chemoradiation, though the difference was not statistically significant. ${ }^{58}$

Considerable efforts have been made to conduct clinical trials investigating the potential benefits of adjuvant chemoradiation. But unfortunately, these trials had to be stopped due to poor patient recruitment.

\section{Radical chemoradiation}

Most of the patients with vulvar carcinoma, especially in countries like India, present as advanced inoperable tumor. In an Indian series, about two-thirds of the patients were found to present in advanced stage (stage III-IV) of the disease..$^{59}$ In such patients and in others, whose comorbidities and other factors make them unsuitable for surgery, definitive chemoradiation or brachytherapy are the possible options. In a first GOG Phase II study, chemoradiation with cisplatin and 5-fluorouracil was investigated for patients with advanced vulvar cancer. ${ }^{60} \mathrm{~A}$ total of $33.8 \%$ patients achieved complete remission. In a subsequent GOG Phase II study, chemoradiation with weekly single-agent cisplatin was studied. Complete clinical response was seen in $66.8 \%$ subjects and $50 \%$ reached complete pathologic remission with acceptable toxicity. ${ }^{61}$ Following these encouraging results, weekly cisplatin may probably be used for chemoradiation although mitomycin $\mathrm{C}$ and 5-flurouracil could also serve as alternative regimens. Tans et al showed complete response rates of $30 \%-70 \%{ }^{62}$

\section{Neoadjuvant treatment in advanced vulva cancer}

The concept of neoadjuvant chemoradiation followed by surgery seems promising and an attractive option in advanced vulvar carcinomas. Chemoradiation may downsize tumor volume, 
and hence help achieve resectability of the tumor. ${ }^{63}$ Radical and mutilating surgeries such as anterior or posterior exenteration may also be avoided following this. However, no randomized trials have been carried out to study this option. According to a recent Cochrane review of 3 published studies, it is suggested that there is no significant difference in overall survival rates or treatment-related adverse events when chemoradiation (primary or neoadjuvant) is compared with primary surgery in locally advanced vulvar carcinoma, bulky stage III-IV. ${ }^{64}$

A prospective multicenter trial in Bueno Aires found that the use of neoadjuvant chemotherapy in selected groups may improve operability, hence favoring organ preservation. Adverse reactions were acceptable in this trial, and local adverse effects that were expected after radiotherapy were also avoided.$^{65}$ Aggressive neoadjuvant chemoradiation had been studied by GOG 101 for patients with unresectable T2 and $\mathrm{T} 3$ lesions. Of the operated patients, $46.7 \%$ had complete response at the time of surgery and $2.8 \%$ had residual disease that was still unresectable. This treatment could be promising in large midline tumors, where surgery may cause loss of clitoris and sphincter functions. ${ }^{66}$ GROINSS V-II , an ongoing trial is looking at whether it is safe to give radiotherapy instead of surgery in sentinel node-positive patients as surgery followed by post-operative radiation leads to increased morbidity.

\section{Management of recurrences}

Identifying the important prognostic factors for recurrences and giving appropriate adjuvant therapy in designated cases and a close follow-up can help in prevention and early diagnosis of recurrences. An increased risk of recurrence has been seen in patients with LN metastases, large size of the tumors, deep invasion, lymphovascular invasion, and close surgical margins. Adequate management of recurrence is determined by its site whether local, groin, or distant. In an 8-year audit at our institute, ${ }^{67}$ there were 17 recurrences $(21.7 \%)$. The 2 -year disease-free survival was $100 \%$ in those with no nodal involvement, $73.5 \%$ in those with unilateral nodal disease, and $60 \%$ in those with bilateral nodal involvement. A majority of patients with local recurrence underwent resurgery and flap reconstruction followed by radiation therapy in those cases where it was not given before. Patient with groin recurrence had a worse prognosis and excision of the involved nodes was followed by radiation therapy. Distant metastasis was dealt with by chemotherapy.

\section{Conclusion}

Management of vulvar cancer is mainly determined by the tumor stage at initial diagnosis and the prognostic factors.
This review is an attempt to give an overview of the current literature and studies on vulvar carcinoma, highlighting previous protocols as well as exploring the future directions of management. Due to the low incidence of the disease, the level of evidence for the various treatment modalities is very scarce. In locally advanced vulvar cancers, the role of neoadjuvant chemotherapy or chemoradiation seems attractive. In early cancers also, organ preservation protocols need to be developed. Hence, prospective controlled trials are urgently required to improve the outcomes in this relatively rare yet aggressive disease.

\section{Disclosure}

The authors report no conflicts of interest in this work.

\section{References}

1. Howlader N, Noone AM, Krapcho M, et al, editors. SEER Cancer Statistics Review, 1975-2014. Bethesda, MD: National Cancer Institute. Available from: https://seer.cancer.gov/csr/1975_2014/.Accessed April 2017.

2. de Martel C, Ferlay J, Franceschi S, et al. Global burden of cancers attributable to infections in 2008: a review and synthetic analysis. Lancet Oncol. 2012;13(6):607-615.

3. Bruni L, Barrionuevo-Rosas L, Albero G, et al. ICO_Information Centre on HPV and Cancer (HPV Information Centre). Human Papillomavirus and Related Diseases in India. Summary Report 27 July 2017.

4. Jones IS, Crandon A, Sanday K. Paget's disease of the vulva: diagnosis and follow-up key to management; a retrospective study of 50 cases from Queensland. Gynecol Oncol. 2011;122(1):42-44.

5. Van der Linden M, Meeuwis KA, Bulten J, Bosse T, van Poelgeest MI, de Hullu JA. Paget disease of the vulva. Crit Rev Oncol Hematol. 2016;101:60-74.

6. Forman D, Bray F, Swaminathan R, Ferlay J, editors. Cancer Incidence in Five Continents 2013. Vol. X (electronic version). Lyon: IARC. Available from: http://ci5.iarc.fr. Accessed May 30, 2012.

7. Singh N, Negi N, Srivastava K, Agarwal G. A cohort study of vulvar cancer over a period of 10 years and review of literature. Indian $J$ Cancer. 2016;53(3):412-415.

8. Montana GS, Kang SK. Carcinoma of the vulva. In: Halperin EC, Parez CA, Brady LW, editors. Perez and Brady's Principles and Practice of Radiation Oncology. 5th ed. London, UK: Lippincott Williams and Wilkins; 2008:1692-1707.

9. Boyce J, Fruchter RG, Kasambilides E, Nicastri AD, Sedlis A, Remy JC. Prognostic factors in carcinoma of the vulva. Gynecol Oncol. 1985;20(3):364-377.

10. Homesley HD, Bundy BN, Sedlis A, et al. Assessment of current international federation of gynecology and obstetrics staging of vulvar carcinoma relative to prognostic factors for survival (a Gynecologic Oncology Group study). Am J Obstet Gynecol. 1991;164(4):997-1004.

11. Beller U, Quinn MA, Benedet JL, et al. Carcinoma of the vulva. Int $J$ Gynecol Obstet. 2006;95:S7-S27.

12. Gaarenstroom KN, Kenter GG, Trimbos JB, et al. Postoperative complications after vulvectomy and inguinofemoral lymphadenectomy using separate groin incisions. Int J Gynecol Cancer. 2003;13(4):522-527.

13. Kirby TO, Rocconi RP, Numnum TM, et al. Outcomes of Stage I/II vulvar cancer patients after negative superficial inguinal lymphadenectomy. Gynecol Oncol. 2005;98(2):309-312.

14. Sowicz MK, Wittekind CH. TNM Classification of Malignant Tumors. 7th ed, Oxford: Whiley Blackwell; 2009.

15. Pecorelli S. Revised FIGO staging for carcinoma of the cervix, vulva and endometrium. Int J Gynaecol Obstet. 2009;105(2):103-104. 
16. Wilkinson EJ, Rico MJ, Pierson KK. Microinvasive carcinoma of the vulva. Int J Gynecol Pathol. 1982;1(1):29-39.

17. Petru E, Lück HJ, Stuart G, Gaffney D, Millan D, Vergote I; Gynecologic Cancer Intergroup (GCIG). Gynecologic cancer intergroup (GCIG) proposals for changes of the current FIGO staging system. Eur J Obstet Gynecol Reprod Biol. 2009;143(2):69-74.

18. Tantipalakorn C, Robertson G, Marsden DE, Gebski V, Hacker NF. Outcome and patterns of recurrence for International Federation of Gynecology and Obstetrics (FIGO) stages I and II squamous cell vulvar cancer. Obstet Gynecol. 2009;113(4):895-901.

19. Homesley HD, Bundy BN, Sedlis A, et al. Assessment of current International Federation of Gynecology and Obstetrics staging of vulvar carcinoma relative to prognostic factors for survival (a Gynecologic Oncology Group study). Am J Obstet Gynecol. 1991;164(4):997-1003; discussion 1003-1004.

20. Rouzier R, Preti M, Sideri M, Paniel BJ, Jones RW. A suggested modification to FIGO stage III vulvar cancer. Gynecol Oncol. 2008;110(1): 83-86.

21. Origoni M, Sideri M, Garsia S, Carinelli SG, Ferrari AG. Prognostic value of pathological patterns of lymph node positivity in squamous cell carcinoma of the vulva stage III and IVA FIGO. Gynecol Oncol. 1992;45(3):313-316.

22. Fons G, Hyde SE, Buist MR, et al. Prognostic value of bilateral positive nodes in squamous cell cancer of the vulva. Int J Gynecol Cancer. 2009;19(7):1276-1280.

23. Podratz KC, Symmonds RE, Taylor WF, Williams TJ. Carcinoma of the vulva: analysis of treatment and survival. Obstet Gynecol. 1983;61(1):63-74.

24. Barton DP. The prevention and management of treatment related morbidity in vulval cancer. Best Pract Res Clin Obstet Gynaecol. 2003;17(4): 683-701.

25. Byron S, Lamb E, Yonemoto R, Kase S. Radical inguinal node dissection in the treatment of cancer. Surg Gynecol Obstet. 1962;114:401-408.

26. Stehman FB, Look KY. Carcinoma of the vulva. Obstet Gynecol. 2006;107:719.

27. Ansink A, van der Velden J. Surgical interventions for early squamous cell carcinoma of the vulva. Cochrane Database Syst Rev. 2000;2:CD002036.

28. Heaps JM, Fu YS, Montz FJ, Hacker NF, Berek JS. Surgical-pathologic variables predictive of local recurrence in squamous cell carcinoma of the vulva. Gynecol Oncol. 1990;38(3):309-314.

29. Burke TW, Levenback C, Coleman RL, Morris M, Silva EG, Gershenson DM. Surgical therapy of T1 and T2 vulvar carcinoma: further experience with radical wide excision and selective inguinal lymphadenectomy. Gynecol Oncol. 1995;57(2):215-220.

30. Farias-Eisner R, Cirisano F, Grouse D, et al. Conservative and individualized surgery for early squamous carcinoma of the vulva: the treatment of choice for stage I and II $\left(\mathrm{T}_{1-2} \mathrm{~N}_{0-1} \mathrm{M}_{0}\right)$ disease. Gynecol Oncol. 1994;53(1):55-58.

31. De Hullu JA, Hollema H, Lolkema S, et al. Vulvar carcinoma. The price of less radical surgery. Cancer. 2002;95(11):2331-2338.

32. Woelber L, Choschzick M, Eulenburg C, et al. Prognostic value of pathological resection margin distance in squamous cell cancer of the vulva. Ann Surg Oncol. 2011;18(3):3811-3818.

33. Imoto $\mathrm{S}$, Inamine $\mathrm{M}, \mathrm{Kudaka} \mathrm{W}$, et al. Prognostic factors in patients with vulvar cancer treated with primary surgery: a single-center experience. Springerplus. 2016;5:125.

34. Hacker NF, Van der Velden J. Conservative management of early vulvar cancer. Cancer. 1993;71(4 Suppl):1673-1677.

35. Homesley HD, Bundy BN, Sedlis A, et al. Prognostic factors for groin node metastasis in squamous cell carcinoma of the vulva (a Gynecologic Oncology Group study). Gynecol Oncol. 1993;49(3):279-283.

36. Iversen T, Aas M. Lymph drainage from the vulva. Gynecol Oncol. 1983;16(2):179-189.

37. Homesley HD, Bundy BN, Sedlis A, Adcock L. Radiation therapy vs pelvic node resection for carcinoma of the vulva with positive groin nodes. Obstet Gynecol. 1986;68(6):733-740.
38. Balat O, Edwards C, Delclos L. Complications following combined surgery (radical vulvectomy vs wide local excision) and radiotherapy for the treatment of carcinoma of the vulva: report of 73 patients. Eur J Gynaecol Oncol. 2000;21(5):501-503.

39. Rutledge FN, Mitchell MF, Munsell MF, et al. Prognostic indicators for invasive carcinoma of the vulva. Gynecol Oncol. 1991;42(3):239-244.

40. DeSimone CP, Van Ness JS, Cooper AL, et al. The treatment of lateral $\mathrm{T} 1$ and T2 squamous cell carcinomas of the vulva confined to the labium majus or minus. Gynecol Oncol. 2007;104(2):390-395.

41. Bell JG, Lee JS, Reid GC. Complete groin lymphadenectomy with preservation of the fascia lata in the treatment of vulvar carcinoma. Gynecol Oncol. 2000;77(2):314-318.

42. Stehman FB, Bundy BN, Dvoretsky PM, Creasman WT. Early stage I carcinoma of the vulva treated with ipsilateral superficial inguinal lymphadenectomy and modified $\mathrm{W}$ hemivulvectomy: a prospective study of the Gynecologic Oncology Group. Obstet Gynecol. 1992;79(4):490-497.

43. Hassanzade M, Attaran M, Treglia G, Yousefi Z, Sadeghi R. Lymphatic mapping and sentinel node biopsy in squamous cell carcinoma of the vulva: systematic review and meta-analysis of the literature. Gynecol Oncol. 2013;130(1):237-245.

44. Moore RG, Granai CO, Gajewski W, Gordinier M, Steinhoff MM. Pathologic evaluation of inguinal sentinel lymph nodes in vulvar cancer patients: a comparison of immunohistochemical staining vs ultrastaging with hematoxylin and eosin staining. Gynecol Oncol. 2003;91(2):378-382.

45. Levenback CF, van der Zee AG, Rob L, et al. Sentinel lymph node biopsy in patients with gynecologic cancers Expert panel statement from the International Sentinel Node Society Meeting, February 21, 2008. Gynecol Oncol. 2009;114(2):151-156.

46. Van der Zee AG, Oonk MH, De Hullu JA, et al. Sentinel node dissection is safe in the treatment of early-stage vulvar cancer. J Clin Oncol. 2008;26(6):884-889.

47. Robison K, Fiascone S, Moore R. Vulvar cancer and sentinel lymph nodes: a new standard of care? Expert Rev Anticancer Ther. 2014;14(9):975-977.

48. Perez CA, Grigsby PW, Chao C, et al. Irradiation in carcinoma of the vulva: factors affecting outcome. Int J Radiat Oncol Biol Phys. 1998;42(2):335-344.

49. Viswanathan AN, Pinto AP, Schultz D, Berkowitz R, Crum CP. Relationship of margin status and radiation dose to recurrence in post-operative vulvar carcinoma. Gynecol Oncol. 2013;130(3):545-549.

50. Katz A, Eifel PJ, Jhingran A, Levenback CF. The role of radiation therapy in preventing regional recurrences of invasive squamous cell carcinoma of the vulva. Int J Radiat Oncol Biol Phys. 2003;57(2):409-418.

51. Faul CM, Mirmow D, Huang Q, Gerszten K, Day R, Jones MW. Adjuvant radiation for vulvar carcinoma: improved local control. Int J Radiat Oncol Biol Phys. 1997;38(2):381-389.

52. Fons G, Groenen SM, Oonk MH, et al. Adjuvant radiotherapy in patients with vulvar cancer and one intra capsular lymph node metastasis is not beneficial. Gynecol Oncol. 2009;114(2):343-345.

53. Parthasarathy A, Cheung MK, Osann K, et al. The benefit of adjuvant radiation therapy in single-node-positive squamous cell vulvar carcinoma. Gynecol Oncol. 2006;103(3):1095-1099.

54. Mahner S, Jueckstock J, Hilpert F, et al. Impact of adjuvant therapy in lymph-node positive vulvar cancer: the AGO CARE 1 study. J Clin Oncol. 2012;30(Suppl):abstract 5007.

55. Homesley HD, Bundy BN, Sedlis A, Adcock L. Radiation therapy vs pelvic node resection for carcinoma of the vulva with positive groin nodes. Obstet Gynecol. 1986;68(6):733-740.

56. Sharma DN, Rath GK, Kumar S, Bhatla N, Julka PK, Sahai P. Treatment outcome of patients with carcinoma of vulva: experience from a tertiary cancer center of India. J Cancer Res Ther. 2010;6(4):503-507.

57. Curry SL, Wharton JT, Rutledge F. Positive lymph nodes in vulvar squamous carcinoma. Gynecol Oncol. 1980;9(1):63-67.

58. Han SC, Kim DH, Higgins SA, Carcangiu ML, Kacinski BM. Chemoradiation as primary or adjuvant treatment for locally advanced carcinoma of the vulva. Int J Radiat Oncol Biol Phys. 2000;47(5):1235-1244. 
59. Bafna UD, Devi UM, Naik KA, Hazra S, Sushma N, Babu N. Carcinoma of the vulva: a retrospective review of 37 cases at a regional cancer center in South India. J Obstet Gynaecol. 2004;24:403-407.

60. Moore DH, Thomas GM, Montana GS, Saxer A, Gallup DG, Olt G. Preoperative chemoradiation for advanced vulvar cancer: a phase II study of the Gynecologic Oncology Group. Int J Radiat Oncol Biol Phys. 1998;42(1):79-85.

61. Moore DH, Ali S, Koh WJ, et al. A phase II trial of radiation therapy and weekly cisplatin chemotherapy for the treatment of locally-advanced squamous cell carcinoma of the vulva: a gynecologic oncology group study. Gynecol Oncol. 2012;124(3):529-533.

62. Tans L, Ansink AC, van Rooij PH, Kleijnen C, Mens JW. The role of chemo-radiotherapy in the management of locally advanced carcinoma of the vulva: single institutional experience and review of literature. $\mathrm{Am}$ J Clin Oncol. 2010;34(1):22-26.

63. Hoffman MS. Squamous-cell carcinoma of the vulva: locally advanced disease. Best Pract Res Clin Obstet Gynaecol. 2003;17(4): 635-647.
64. Shylasree TS, Bryant A, Howells RE. Chemoradiation for advanced primary vulval cancer. Cochrane Database Syst Rev. 2011;4:CD003752.

65. Aragona AM, Cuneo N, Soderini AH, et al. Tailoring the treatment of locally advanced squamous cell carcinoma of the vulva: neoadjuvant chemotherapy followed by radical surgery: results from a multicenter study. Int J Gynecol Cancer. 2012;22(7):1258-1263.

66. Montana GS, Thomas GM, Moore DH, et al. Preoperative chemo-radiation for carcinoma of the vulva with N2/N3 nodes. A gynecologic oncology group study. Int J Radiat Oncol Biol Phys. 2000;48(4):1007-1013.

67. Batra Modi K, Sekhon R, Shah S, et al. Recurrent cancer of the vulva: clinicopathologic prognostic factors, patterns of recurrence, and their management. J Gynecol Surg. 2016;32(6):339-344.

68. Farias-Eisner R, Cirisano FD, Grouse D et al. Conservative and individualized surgery for early squamous carcinoma of the vulva: the treatment of choice for stage I and II (T1-2 N0-1 M0) disease. Gynecol Oncol. 1994;53:55-58.

69. De Hullu JA, Hollema H, Lolkema S, et al. Vulvar carcinoma. The price of less radical surgery. Cancer. 2002;95,2331-2338.
Cancer Management and Research

\section{Publish your work in this journal}

Cancer Management and Research is an international, peer-reviewed open access journal focusing on cancer research and the optimal use of preventative and integrated treatment interventions to achieve improved outcomes, enhanced survival and quality of life for the cancer patient. The manuscript management system is completely online and includes

\section{Dovepress}

a very quick and fair peer-review system, which is all easy to use. Visit http://www.dovepress.com/testimonials.php to read real quotes from published authors. 